\title{
Characterization of Pseudoalteromonas distincta-like sea-water isolates and description of Pseudoalteromonas aliena sp. nov.
}

Correspondence

Elena P. Ivanova eivanova@swin.edu.au
Elena P. Ivanova, ${ }^{1,2}$ Nataliya M. Gorshkova, ${ }^{2}$ Natalia V. Zhukova, ${ }^{3}$ Anatolii M. Lysenko, ${ }^{4}$ Elena A. Zelepuga, ${ }^{2}$ Nina G. Prokof'eva, ${ }^{2}$ Valery V. Mikhailov, ${ }^{2}$ Dan V. Nicolau ${ }^{1}$ and Richard Christen ${ }^{5}$

\author{
${ }^{1}$ Industrial Research Institute Swinburne, Swinburne University of Technology, PO Box 218, \\ Hawthorn, Victoria 3122, Australia \\ ${ }^{2}$ Pacific Institute of Bioorganic Chemistry of the Far-Eastern Branch of the Russian Academy \\ of Sciences, 690022 Vladivostok, Prospekt 100 Let Vladivostoku 159, Russia \\ ${ }^{3}$ Institute of Marine Biology of the Far-Eastern Branch of the Russian Academy of Sciences, \\ 690041 Vladivostok, Russia \\ ${ }^{4}$ Institute of Microbiology of the Russian Academy of Sciences, 117811 Moscow, Russia \\ ${ }^{5}$ UMR6543 CNRS-Université de Nice Sophia Antipolis, Centre de Biochimie, Parc Valrose, \\ F06108 Nice cedex 2, France
}

Marine, aerobic, heterotrophic bacteria of the genus Pseudoalteromonas (Gauthier et al., 1995) have recently received significant levels of attention because they are readily cultivated and are widespread in the marine environment. Pseudoalteromonas is one of the largest genera within the $\gamma$-Proteobacteria and currently comprises more than 30 species (Ivanova \& Mikhailov, 2001).

The GenBank accession number for the 16S rRNA gene sequence of Pseudoalteromonas aliena KMM $3562^{\top}$ is AY387858.

A phylogenetic tree, a comparison of fatty acid compositions and details of the phenotypic features that distinguish $P$. aliena sp. nov. from most other phylogenetically related species of the genus are available as supplementary material in IJSEM Online.
During the course of our studies on the biodiversity of marine Proteobacteria, we isolated a collection of Alteromonaslike bacteria from the North-West Pacific (Ivanova et al., 1996, 1998, 2000b, 2002). Of these, seven strains were phenotypically similar to Pseudoalteromonas distincta. Since the description of the species $P$. distincta was based on a single strain isolated from a marine sponge collected at a depth of $350 \mathrm{~m}$ near the Komandorskie Islands, Russia (Romanenko et at., 1995; Ivanova et al., 2000b), detailed study of the novel isolates originating from sea water was of particular interest.

The strains examined in this study were isolated from a few samples of sea water collected in June 1999 at a depth of 0-1 m (salinity, $31 \%$; temperature, $10{ }^{\circ} \mathrm{C}$ ) in Amursky Bay (near Vladivostok, Russia) of the Sea of Japan. The strains 
were isolated by plating $(0.1 \mathrm{ml})$ on agar plates of marine agar 2216 (Difco) and on plates with medium B. Medium B contained $0 \cdot 2 \%(\mathrm{w} / \mathrm{v})$ Bacto peptone (Difco), $0 \cdot 2 \%$ $(\mathrm{w} / \mathrm{v})$ casein hydrolysate (Merck), $0 \cdot 2 \%(\mathrm{w} / \mathrm{v})$ Bacto yeast extract (Difco), $0 \cdot 1 \%(\mathrm{w} / \mathrm{v})$ glucose, $0 \cdot 02 \%(\mathrm{w} / \mathrm{v}) \mathrm{KH}_{2} \mathrm{PO}_{4}$, $0.005 \%$ (w/v) $\mathrm{MgSO}_{4} .7 \mathrm{H}_{2} \mathrm{O}, 1.5 \%$ (w/v) Bacto agar (Difco), $50 \%(\mathrm{v} / \mathrm{v})$ natural sea water and $50 \%(\mathrm{v} / \mathrm{v})$ distilled water at $\mathrm{pH} 7 \cdot 5-7 \cdot 8$, as described elsewhere (Ivanova et al., 1996). After initial isolation, the strains were purified on medium $B$ and maintained on the same semi-solid medium $B$ in tubes under mineral oil at $4{ }^{\circ} \mathrm{C}$ and stored at $-80^{\circ} \mathrm{C}$ in marine broth (Difco) supplemented with $30 \%(\mathrm{v} / \mathrm{v})$ glycerol. All isolates were streaked on agar plates from broth cultures every 6 months to ensure purity and viability.

The following physiological and biochemical properties were examined: oxidation/fermentation of glucose, denitrification (Azegami et al., 1987), oxidase and catalase activity, gelatin liquefaction, arginine dihydrolase activity, lysine decarboxylase activity, ornithine decarboxylase activity, sodium requirement $(\mathrm{NaCl}$ at $0,0 \cdot 5,1,3,6,8$ and $10 \%$, w/v), indole and $\mathrm{H}_{2} \mathrm{~S}$ production and the ability to hydrolyse starch, Tween 80 and casein (determined using methods described by Smibert \& Krieg, 1994). Growth at different temperatures was determined in marine broth 2216 (Difco) and on plates with medium B after $24-72 \mathrm{~h}$ at 2, 4, 6, 29, 30, 31,32 and $33^{\circ} \mathrm{C}$. Degradation of macromolecules by the strains was tested using medium B. Chitin $(1 \%$, w/v) and alginate (sodium salt) $(0 \cdot 1 \%, \mathrm{w} / \mathrm{v})$ hydrolysis was determined by assessing the development of clear zones around the colonies. The Biolog GN test kit was also used to examine the primary oxidation of 95 carbon compounds, as described elsewhere (Ivanova et al., 1998). Susceptibility to antibiotics was tested by using the conventional diffusion plate technique, using solid medium B and discs impregnated with antibiotics. Antibacterial activity was determined by using the agar diffusion assay, based on the method described by Barry (1980). Haemolysis was tested on Merck blood agar plates (6.5\% sheep blood). Cytotoxicity on Ehrlich ascites carcinoma cells was tested on butanol extracts of the strains (Sasaki et al., 1985). Bacterial cells from a $100 \mathrm{ml}$ culture were extracted with butanol $(100 \mathrm{ml})$ and evaporated under reduced pressure. The method described by Prokof eva et al. (2003) was employed to study haemolytic activity. Briefly, an erythrocyte suspension was prepared in $66 \mathrm{mM}$ PBS $(120 \mathrm{mM} \mathrm{NaCl}$,

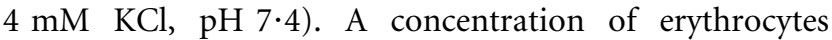
giving an optical density $\left[\mathrm{OD}_{700}\right.$; Specord M40 UV spectrophotometer (Zeiss); cuvette path length, $1 \mathrm{~cm}$ ] of $1 \cdot 0$ for non-haemolysed samples was used. The haemolytic activity of a sample was expressed as the concentration causing $50 \%$ haemolysis.

Phenotypic analysis showed that all isolates were essentially identical to each other, Gram-negative, strictly aerobic, oxidase- and catalase-positive, did not produce $\mathrm{H}_{2} \mathrm{~S}$ or indole and were negative for denitrification. The novel isolates did not show antibacterial activity, but demonstrated a cytotoxic effect on tumour cells [inhibitor concentration needed to inhibit viability of $50 \%$ of tumour cells $\left.\left(\mathrm{IC}_{50}\right)=80-100 \mu \mathrm{g} \mathrm{ml}^{-1}\right]$. All of the novel strains grew well between 4 and $29^{\circ} \mathrm{C}$, in contrast to $P$. distincta, which grew between 6 and $33^{\circ} \mathrm{C}$. The novel organisms were also less halophilic, tolerating only limited salinity for growth; four of seven isolates grew on nutrient media containing only 3-6\% (w/v) NaCl, whereas P. distincta tolerated up to $10 \%$ $(\mathrm{w} / \mathrm{v}) \mathrm{NaCl}$ (though, according to the original description, $P$. distincta only tolerated $\mathrm{NaCl}$ concentrations of up to $6 \%, \mathrm{w} / \mathrm{v})$. Optimum growth occurred at $23^{\circ} \mathrm{C}$ on nutrient media containing $3 \%(\mathrm{w} / \mathrm{v}) \mathrm{NaCl}$. Unlike P. distincta, the seven organisms studied were haemolytic, cytotoxic and hydrolysed starch and casein. In addition, the novel isolates and $P$. distincta had different antibiotic-susceptibility patterns. For example, $P$. distincta was susceptible to kanamycin and neomycin but not susceptible to carbenicillin the opposite of the pattern for the sea-water strains. The results of examination of the morphological and physiological properties are shown in Table 1 and in the species description (see also the Supplementary Table available in IJSEM Online).

To study the cellular fatty acid composition, all strains were grown on solid medium B (described above) at $28^{\circ} \mathrm{C}$ for $24 \mathrm{~h}$. Fatty acids were analysed by GLC as described previously by Svetashev et al. (1995). The fatty acid patterns of the five strains studied were very similar and were also very like those found for other Pseudoalteromonas species (Ivanova et al., 2000a). The levels of the major fatty acids ranged from $4 \cdot 8$ to $7 \cdot 4 \%$ for $15: 0$, from $7 \cdot 2$ to $13 \cdot 8 \%$ for $16: 0$, from $29 \cdot 2$ to $28 \cdot 8 \%$ for $6: 1(\mathrm{n}-7)$, from $19 \cdot 7$ to $23 \cdot 5 \%$ for $17: 1(n-8)$ and from $1 \cdot 1$ to $1 \cdot 6 \%$ for $18: 1(n-7)$. Cluster analysis based on cellular fatty acid profiles was performed by using STATISTICA for Windows, release 5.1 (StatSoft). An unweighted pair group averages method was used for cluster analysis, and a diagram was drawn in Euclidian distance scale as recommended by MIDI (Sasser, 1997). The novel isolates, $P$. distincta and other species of the genus Pseudoalteromonas formed a few clusters at Euclidian distances from 10 to 15 , which related them at the 'genus' level (see Supplementary Fig. A in IJSEM Online). The novel sea-water isolates grouped within a lower Euclidian distance, indicating that they belong to the same species.

Production of pigment was studied in media B and BT (medium B supplemented with $0 \cdot 1 \%$ L-tyrosine, w/v). Synthetic medium of the following composition $(\mathrm{w} / \mathrm{v})$ was also used: $0.05 \% \quad \mathrm{KH}_{2} \mathrm{PO}_{4}, 0.05 \% \mathrm{~K}_{2} \mathrm{HPO}_{4}, 0.005 \%$ $\mathrm{MgSO}_{4} .7 \mathrm{H}_{2} \mathrm{O}, 0.06 \% \mathrm{CuSO}_{4}, 0.005 \% \mathrm{CaCl}_{2}, 0.002 \%$ mg L-methionine, $\quad 0.002 \%$ DL-tryptophan, $0.001 \%$ $\alpha$-asparagine, $\quad 0.001 \%$ DL-phenylalanine, $0.2 \%$ yeast extract, $0 \cdot 1 \%\left(\mathrm{NH}_{4}\right)_{2} \mathrm{SO}_{4}(\mathrm{pH} 7 \cdot 6)$; $\mathrm{ST}$ medium had the same composition but with the addition of L-tyrosine at $0 \cdot 1 \%(\mathrm{w} / \mathrm{v})$. BT-basal medium was also used with inhibitors of melanogenesis (L-cysteine, EDTA, ascorbic acid). All inhibitors were added at a final concentration of 1$10 \mathrm{mM}$. Solubility of pigments was tested with $0.5 \mathrm{ml}$ 
Table 1. Phenotypic characteristics of strains of $P$. distincta and $P$. aliena sp. nov.

All strains are Gram-negative, are positive for oxidase, catalase, lipase and gelatinase activity, grow at $6-29{ }^{\circ} \mathrm{C}$ and in $3-6 \%$ (w/v) $\mathrm{NaCl}$, do not utilize D-galactose, D-arabinose, D-ribose, D-sorbitol, glycerol, xylose, melibiose, adonitol, rhamnose or myo-inositol and are not susceptible to benzylpenicillin $(10 \mathrm{U})$, lincomycin $(15 \mu \mathrm{g})$ or tetracycline $(30 \mu \mathrm{g}) .+$, Positive; - , negative; W, weak reaction.

\begin{tabular}{|c|c|c|c|c|c|c|c|c|}
\hline \multirow[t]{2}{*}{ Characteristic } & \multirow{2}{*}{$\begin{array}{l}\text { P. distincta } \\
\mathrm{KMM} 638^{\mathrm{T}}\end{array}$} & \multicolumn{7}{|c|}{ P. aliena sp. nov. } \\
\hline & & $\begin{array}{l}\text { KMM } \\
3562^{\mathrm{T}}\end{array}$ & $\begin{array}{c}\text { KMM } \\
3536\end{array}$ & $\begin{array}{c}\text { KMM } \\
3537\end{array}$ & $\begin{array}{c}\text { KMM } \\
3538\end{array}$ & $\begin{array}{c}\text { KMM } \\
3539\end{array}$ & $\begin{array}{c}\text { KMM } \\
3615\end{array}$ & $\begin{array}{c}\text { KMM } \\
3629\end{array}$ \\
\hline Production of melanin-like pigments & + & + & $\mathrm{W}$ & + & + & + & + & + \\
\hline \multicolumn{9}{|l|}{ Growth at: } \\
\hline $4^{\circ} \mathrm{C}$ & - & + & + & + & + & + & + & + \\
\hline $30^{\circ} \mathrm{C}$ & + & + & + & + & - & - & - & + \\
\hline $31^{\circ} \mathrm{C}$ & + & - & + & + & - & - & - & + \\
\hline $32^{\circ} \mathrm{C}$ & + & - & - & - & - & - & - & + \\
\hline $33^{\circ} \mathrm{C}$ & + & - & - & - & - & - & - & - \\
\hline \multicolumn{9}{|l|}{ Growth in $\mathrm{NaCl}$ at: } \\
\hline $0.5 \%(\mathrm{w} / \mathrm{v})$ & + & - & + & + & - & - & - & + \\
\hline $1 \%(\mathrm{w} / \mathrm{v})$ & + & - & + & + & - & - & - & + \\
\hline $8 \%(w / v)$ & $+^{*}$ & - & - & - & - & - & - & - \\
\hline \multicolumn{9}{|l|}{ Production of: } \\
\hline Caseinase & $-{ }^{*}$ & + & - & - & + & + & + & + \\
\hline Amylase & - & + & + & + & + & + & + & + \\
\hline Haemolysis & - & + & + & + & + & + & + & + \\
\hline \multicolumn{9}{|l|}{ Assimilation of: } \\
\hline Sucrose & - & + & - & - & + & + & + & - \\
\hline Maltose & - & $\mathrm{W}$ & $\mathrm{W}$ & $\mathrm{W}$ & $\mathrm{W}$ & $\mathrm{W}$ & $\mathrm{W}$ & $\mathrm{W}$ \\
\hline D-Glucose & - & $\mathrm{W}$ & - & - & $\mathrm{W}$ & $\mathrm{W}$ & $\mathrm{W}$ & - \\
\hline D-Mannitol & - & $\mathrm{w}$ & - & - & $\mathrm{w}$ & $\mathrm{W}$ & $\mathrm{w}$ & - \\
\hline$N$-Acetylglucosamine & - & $\mathrm{W}$ & $\mathrm{W}$ & $\mathrm{W}$ & $\mathrm{W}$ & $\mathrm{W}$ & $\mathrm{W}$ & $\mathrm{W}$ \\
\hline \multicolumn{9}{|l|}{ Susceptibility to: $\dagger$} \\
\hline Ampicillin $(10 \mu \mathrm{g})$ & 0 & 0 & 15 & 0 & 12 & 0 & 0 & 0 \\
\hline Gentamicin $(10 \mu \mathrm{g})$ & 19 & 15 & 23 & 17 & 20 & 18 & 13 & 15 \\
\hline Kanamycin $(30 \mu \mathrm{g})$ & 13 & 0 & 0 & 0 & 0 & 0 & 0 & 0 \\
\hline Carbenicillin (100 ED) & 0 & 0 & 20 & 11 & 20 & 0 & 0 & 0 \\
\hline Neomycin $(30 \mu \mathrm{g})$ & 17 & 0 & 0 & 0 & 11 & 0 & 0 & 0 \\
\hline Oleandomycin $(15 \mu \mathrm{g})$ & 0 & 15 & 15 & 20 & 20 & 18 & 15 & 14 \\
\hline Polymyxin (300 ED) & 10 & 11 & 12 & 15 & 13 & 10 & 11 & 10 \\
\hline Streptomycin $(30 \mu \mathrm{g})$ & 18 & 15 & 22 & 18 & 20 & 18 & 13 & 15 \\
\hline $\mathrm{G}+\mathrm{C}$ content $(\mathrm{mol} \%)$ & $43 \cdot 6$ & $41 \cdot 1-42 \cdot 5 \ddagger$ & & & & & & \\
\hline
\end{tabular}

${ }^{\star}$ Data obtained in this study.

$\dagger$ Values are diameters of the growth inhibition zone (in $\mathrm{mm}$ ).

$\ddagger$ Range for the seven strains shown.

culture fluid in $2 \mathrm{ml}$ aliquots of various solvents. Pigments were designated soluble if the solvent was coloured after agitation, and insoluble otherwise. A distinctive feature of the type strain of $P$. distincta is its ability to produce a melanin-like pigment. The isolated strains appeared to synthesize a diffusible brown/black pigment when grown on common media such as marine agar 2216 or medium B. We examined the formation of pigment by the type strain on tyrosine-containing media that are optimal for melanogenesis, and in the same media in the presence of inhibitors of melanogenesis, namely cysteine, EDTA and ascorbic acid. Pigment extracted from cells with a $0.5 \mathrm{M}$ solution of $\mathrm{NaOH}$ in water formed a brown solution. The alkaline pigment solution reacted qualitatively as melanin: it became colourless upon the addition of $\mathrm{H}_{2} \mathrm{O}_{2}$; addition of $\mathrm{KMnO}_{4}$ gave a green solution. The absorption maximum of the pigment, i.e. $225 \mathrm{~nm}$, was close to that for synthetic melanin (Sigma), which is $223 \mathrm{~nm}$, confirming the melanin-like nature of the pigments tested.

Tyrosinase activity was tested according to the method of Pomerantz \& Murphy (1974) in crude enzyme extracts, as 
described elsewhere (Ivanova et al., 2003), then estimated spectrophotometrically by measuring the rate of formation of dopachrome from L-tyrosine at $35^{\circ} \mathrm{C}$ under the following conditions: L-tyrosine, $5 \mu \mathrm{mol}$; 3,4-dihydroxyL-phenylalanine, $0.5 \mu \mathrm{mol}$; sodium phosphate buffer (pH 6.8), $30 \mu \mathrm{mol}$; enzyme, 0.001-0.05 U; total volume, $1.00 \mathrm{ml}$. One unit of enzyme activity was estimated as the amount of enzyme required to produce $1 \mu \mathrm{mol}$ dopachrome $\mathrm{min}^{-1}$ from tyrosine under the above conditions. The molar absorbance coefficient of dopachrome is 3700 at $475 \mathrm{~nm}$. It appeared that an active melanogenesis took place when the strains studied had reached stationary phase in complex or chemically defined media containing tyrosine. The tyrosinase activity was quantitatively determined in cells and cell supernatants (Table 2). The results obtained indicated that the novel isolates showed significant enzyme activity that ranged between 30 and $107 \mathrm{U} \mathrm{mg}^{-1}$ and was nearly $2 \cdot 5$ times greater than that of $P$. distincta. In general, tyrosinase production was highly dependent on culture medium composition. For example, the presence of ascorbic acid induced both enzyme synthesis and 3,4-dihydroxy-L-phenylalanine production. The possible physiological role of melanin pigments, tyrosinases and related enzymes as important factors in resistance against stress factors such as UV radiation and oxidative damage, the degradation of high-molecular-mass compounds of phenolic nature and the regulation of enzyme activities by environmental signals have been discussed elsewhere (Lucas-Elío et al., 2002).

The 16S rRNA gene was amplified and sequenced by MIDI Labs. Primers used for the amplification corresponded to
Escherichia coli positions 5 and 1540; the details are as described elsewhere (Ivanova et al., 2004). The novel $16 \mathrm{~S}$ rRNA gene sequence was added, aligned and compared with a database of 80000 previously aligned sequences. This analysis and BLAST queries against the latest release of the Bacteria division of GenBank allowed us to select the 100 most closely related sequences (see Supplementary Fig. B in IJSEM Online) for further analysis. Finally, 23 sequences, mainly those of type strains, were selected; phylogenetic trees were constructed according to three different methods [BioNJ (neighbour-joining), ML (maximumlikelihood using the GLOBAL option) and MP (maximumparsimony)]. The BioNJ program from Gascuel (1997) and the ML and MP programs were from PHYLIP (Phylogeny Inference Package, version 3.573c, distributed by J. Felsenstein, Department of Genetics, University of Washington, Seattle, WA, USA). For the NJ analysis, distances were calculated according to the Kimura twoparameter correction Gascuel (1997). Bootstraps were done using BioNJ and 1000 replications. Phylogenetic trees were drawn using NJPLOT (Perrière \& Gouy, 1996). Domains used to construct the final phylogenetic trees (positions 86-1396 of KMM $3562^{\mathrm{T}}$ ) were available for all sequences. All analyses revealed that strain KMM $3562^{\mathrm{T}}$ is included in the clade formed by the genus Pseudoalteromonas. The topology of the phylogenetic tree shown in Fig. 1 is that of the bootstrap analysis, as it has been demonstrated that this topology is often better than that of a simple NJ analysis (Gascuel, 1997); see also the discussion in Ivanova et al. (2004). Percentages of 16S RNA gene sequence similarity with most similar sequences were calculated by parsing the non-overlapping high-scoring segment pair resulting from

Table 2. Comparative enzyme activities of melanogenic $P$. distincta, $P$. aliena and $P$. nigrifaciens strains

One unit of tyrosinase activity is the amount of enzyme required to produce $1 \mu \mathrm{mol}$ dopachrome from tyrosine $\min ^{-1}$.

\begin{tabular}{|c|c|c|c|c|}
\hline \multirow[t]{2}{*}{ Strain } & \multirow{2}{*}{$\begin{array}{c}\text { Protein } \\
{\left[\mathrm{U}(\mathrm{mg} \text { wet cells })^{-1}\right]}\end{array}$} & \multirow{2}{*}{$\begin{array}{l}\text { 3,4-Dihydroxy-L-phenylalanine } \\
\left(\mathrm{mg} \mathrm{ml}^{-1}\right)\end{array}$} & \multicolumn{2}{|c|}{ Tyrosinase activity } \\
\hline & & & $\mathrm{U} \mathrm{ml}^{-1}$ & $\mathrm{U} \mathrm{mg}^{-1}$ \\
\hline \multicolumn{5}{|l|}{ P. distincta } \\
\hline KMM $638^{\mathrm{T}}$ & 76 & $0 / 0$ & $12 / 1$ & $9 \cdot 3 / 0 \cdot 9$ \\
\hline KMM $638^{\mathrm{T}} \dagger$ & 98 & $0 \cdot 01 / 1 \cdot 7$ & $90 \cdot 1 / 2 \cdot 3$ & $12 \cdot 8 / 15$ \\
\hline \multicolumn{5}{|c|}{ P. aliena sp. nov. } \\
\hline KMM $3562^{\mathrm{T}}$ & 270 & $0 \cdot 027 / 0 \cdot 007$ & $135 \cdot 1 / 1 \cdot 09$ & $30 \cdot 5 / 10 \cdot 9$ \\
\hline $\mathrm{KMM} 3562^{\mathrm{T}} \dagger$ & 320 & $0 \cdot 027 / 0 \cdot 007$ & $206 \cdot 6 / 1 \cdot 17$ & $82 \cdot 6 / 11$ \\
\hline KMM 3536 & 300 & $0 \cdot 015 / 0 \cdot 01$ & $269 \cdot 6 / 2 \cdot 03$ & $107 \cdot 84 / 5 \cdot 075$ \\
\hline KMM 3537 & 80 & $0 \cdot 005 / 0$ & $71 \cdot 62 / 0$ & $45 \cdot 6 / 0$ \\
\hline KMM 3538 & 170 & $0 \cdot 02 / 0 \cdot 12$ & $162 \cdot 2 / 1 \cdot 35$ & $49 \cdot 9 / 13 \cdot 5$ \\
\hline KMM 3539 & 260 & $0 \cdot 038 / 0 \cdot 008$ & $233 \cdot 8 / 0$ & $32 \cdot 35 / 0$ \\
\hline KMM 3615 & 70 & $0 \cdot 01 / 0$ & $78 \cdot 4 / 0$ & $31 \cdot 35 / 0$ \\
\hline KMM 3629 & 250 & $0 \cdot 026 / 0 \cdot 007$ & $234 \cdot 5 / 3 \cdot 8$ & $97 \cdot 7 / 38$ \\
\hline \multicolumn{5}{|l|}{ P. nigrifaciens } \\
\hline IAM $13010^{\mathrm{T}}$ & $0 / 0$ & $0 \cdot 01 / 0$ & $0 / 0$ & $0 / 0$ \\
\hline
\end{tabular}

*Values give activity in bacterial cells/supernatant.

$\dagger$ Enzyme activities after growth on BT medium containing ascorbic acid. 


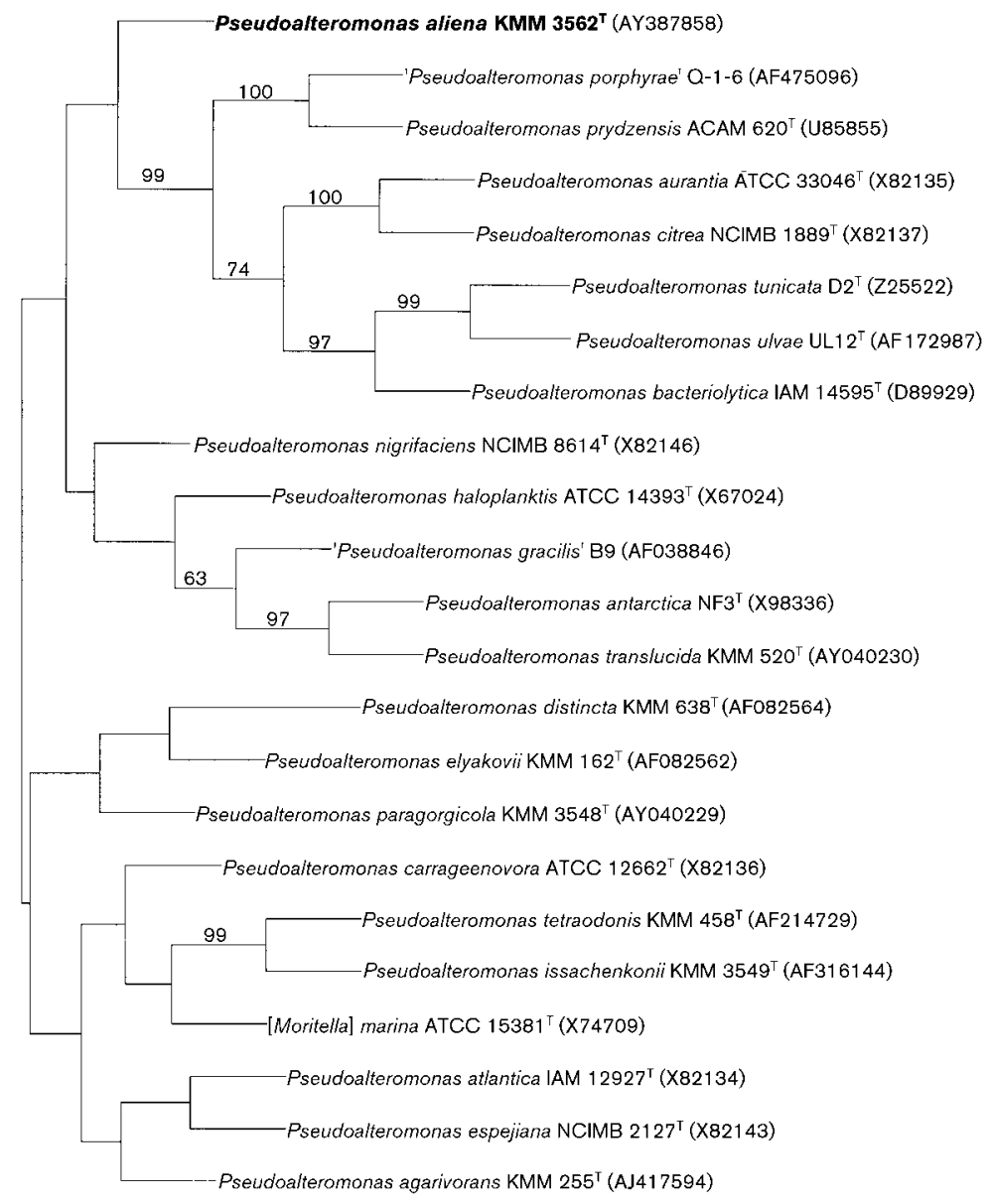

Fig. 1. Phylogenetic position of $P$. aliena sp. nov. according to $16 \mathrm{~S}$ rRNA gene sequence analysis. The topology shown was obtained using the bioNJ algorithm and 1000 bootstrap replications with a Kimura two-parameter correction for the distances. Bootstrap percentages are indicated only for branches that were also retrieved by maximum parsimony and maximum likelihood $(P<0.01)$; these branches should be considered as the only robust clusters identified by this analysis.

a BLAST analysis of KMM $3562^{\mathrm{T}}$ on the Bacteria division, with the options no filter and $\mathrm{W}=7$ : they ranged from 98 to $99 \%$ among non-pigmented species of the genus. These results provided additional evidence that $16 \mathrm{~S}$ rRNA gene sequences can provide only a preliminary assignment of species identity in a genus. The same situation was reported for all other non-pigmented species of the genus Pseudoalteromonas (Gauthier et al., 1995) and for some other genera, e.g. Psychrobacter (Bowman et al., 1996), Pseudomonas (Anzai et al., 2000), etc. The phylogenetic analyses of the 16S rRNA gene sequences also revealed that the novel isolate could not be robustly grouped with any other recognized species including $P$. distincta (shown in Fig. 1).

The DNA was isolated according to the method of Marmur (1961) and the G $+C$ content of the DNA was determined using the thermal denaturation method of Marmur \& Doty (1962). The $G+C$ contents of the DNAs of the strains were 41-43 mol\%. DNA-DNA hybridization was performed spectrophotometrically as described by De Ley et al. (1970). DNA-DNA hybridization data revealed the high interspecies levels of DNA relatedness among the six strains (92-97\%). DNA from the type strain $P$. distincta KMM $638^{\mathrm{T}}$ showed a rather high degree of genetic relatedness (63-65\%) with the newly isolated bacteria. Yet these values are lower than $70 \%$, which is the cut-off value for the definition of genomic species (Wayne et al., 1987).

The novel isolates can be clearly distinguished from other non-pigmented species and, in particular, from $P$. distincta KMM $638^{\mathrm{T}}$ by the combination of phenotypic, genotypic and phylogenetic features, e.g. range of salinity and temperature for growth, presence of haemolytic and cytotoxic activity, ability to hydrolyse starch and casein, different antibiotic-susceptibility patterns (as shown in Table 1 and the Supplementary Table) and by the lack of a robust phylogenetic clade with any species of the genus. Bacteria of the novel species can also be distinguished from phylogenetically related species mainly by salinity tolerance, carbon-source utilization and a number of other phenotypic traits (Supplementary Table). In particular, they are distinct from Pseudoalteromonas haloplanktis in terms of the different temperature and salinity ranges for growth, susceptibility to antibiotics and carbon-source utilization, from Pseudoalteromonas translucida in terms of tolerance to $\mathrm{NaCl}$, ability to decompose starch and the inability to decompose elastin and alginate, from Pseudoalteromonas 
prydzensis and Pseudoalteromonas issachenkonii by the inability to decompose chitin and from Pseudoalteromonas atlantica, Pseudoalteromonas nigrifaciens and Pseudoalteromonas undina by susceptibility to antibiotics and by carbonsource utilization. Therefore, we propose that the seven novel isolates be assigned to a novel species, namely Pseudoalteromonas aliena sp. nov.

\section{Description of Pseudoalteromonas aliena sp. nov.}

Pseudoalteromonas aliena (a'li.e.na. L. fem. adj. aliena another's, stranger, belonging to another species).

Rod-shaped cells, single, about $0 \cdot 7-0.9 \mu \mathrm{m}$ in diameter. Gram-negative. Motile, with a single polar flagellum. Aerobic. Chemorganotroph with respiratory metabolism. Colonies are uniformly round, $2-3 \mathrm{~mm}$ in diameter, regular, convex, smooth. A brown, diffusible, melanin-like pigment is produced around colonies after incubation for $48 \mathrm{~h}$ on marine agar or medium B. Does not form endospores. Does not accumulate poly- $\beta$-hydroxybutyrate as an intracellular reserve product, and has an arginine dihydrolase system. Oxidase- and catalase-positive. Requires $\mathrm{Na}^{+}$ ion or sea water for growth. Growth occurs in media with $0 \cdot 5-6 \%(\mathrm{w} / \mathrm{v}) \mathrm{NaCl}$, and for some strains in media with $3-6 \%(\mathrm{w} / \mathrm{v}) \mathrm{NaCl}$. Temperature for growth ranges from 4 to $29^{\circ} \mathrm{C}$ (some strains grow at $33^{\circ} \mathrm{C}$ ), with optima at $22-$ $25^{\circ} \mathrm{C}$. No growth is detected at $37^{\circ} \mathrm{C}$. The $\mathrm{pH}$ for growth ranges from $6 \cdot 0$ to $10 \cdot 0$, with optima at $7 \cdot 5-8 \cdot 0$. Cytotoxic and haemolytic. Gelatin, starch, alginate and Tween 80 are decomposed. Some strains decompose casein. A limited range of carbon sources are utilized: some strains utilize sucrose and weakly utilize D-glucose, D-mannitol and maltose. Susceptible to gentamicin, oleandomycin, polymyxin and streptomycin; not susceptible to benzylpenicillin, kanamycin, lincomycin, neomycin or tetracycline. The main cellular fatty acids are $16: 1(\mathrm{n}-7), 16: 0,17: 1(\mathrm{n}-8)$ and $18: 1(\mathrm{n}-7)$ (approx. $80 \%)$. The G $+\mathrm{C}$ content of the DNA is $41-43 \mathrm{~mol} \%$.

Isolated from sea-water samples collected from Amursky Bay, Sea of Japan, Pacific Ocean. The type strain is strain SW $19^{\mathrm{T}}\left(=\right.$ KMM $3562^{\mathrm{T}}=$ LMG $\left.22059^{\mathrm{T}}\right)$.

\section{Acknowledgements}

This study was partially supported by funds from grant 2-2.16 from the Ministry for Industry, Science and Technologies of the Russian Federation, grant 02-04-49517 from the Russian Foundation for Basic Research, grant 03-1-0-05-005 from the Far-Eastern Branch of the Russian Academy of Sciences, grant DP 0450012 from the Australian Research Council and grant N66001-00-18952 from the Defence Advanced Research Projects Agency (DARPA).

\section{References}

Anzai, Y., Kim, H., Park, J. Y., Wakabayashi, H. \& Oyaizu, H. (2000). Phylogenetic affiliation of the pseudomonads based on 16S rRNA sequence. Int J Syst Evol Microbiol 50, 1563-1589.
Azegami, K., Nishiyama, K., Watanabe, Y., Kadota, I., Ohuchi, A. \& Fukazawa, C. (1987). Pseudomonas plantarii sp. nov., the causal agent of rice seeding blight. Int J Syst Bacteriol 37, 144-152.

Barry, A. I. (1980). Procedures and theoretical considerations for testing antimicrobial agents in agar media. In Antibiotics in Laboratory Medicine, pp. 10-16. Edited by V. Logan. Baltimore: William \& Wilkins.

Bowman, J. P., Cavanagh, J., Austin, J. J. \& Sanderson, K. (1996). Novel Psychrobacter species from Antarctic ornithogenic soils. Int $J$ Syst Bacteriol 46, 841-848.

De Ley, J., Cattoir, H. \& Reynaerts, A. (1970). The quantitative measurement of DNA hybridization from renaturation rates. Eur J Biochem 12, 133-142.

Gascuel, O. (1997). BIONJ: an improved version of the NJ algorithm based on a simple model of sequence data. Mol Biol Evol 14, 685-695.

Gauthier, G., Gauthier, M. \& Christen, R. (1995). Phylogenetic analysis of the genera Alteromonas, Shewanella, and Moritella using genes coding for small-subunit rRNA sequences and division of the genus Alteromonas into two genera, Alteromonas (emended) and Pseudoalteromonas gen. nov., and twelve new species combinations. Int J Syst Bacteriol 45, 755-761.

Ivanova, E. P. \& Mikhailov, V. V. (2001). A new family of Alteromonadaceae fam. nov., including the marine proteobacteria Alteromonas, Pseudoalteromonas, Idiomarina, and Colwellia. Microbiology (English translation of Mikrobiologiya) 70, 15-23.

Ivanova, E. P., Kiprianova, E. A., Mikhailov, V. V., Levanova, F. G., Garagulya, A. G., Gorshkova, N. M., Yumoto, N. \& Yoshikawa, S. (1996). Characterization and identification of marine Alteromonas nigrifaciens strains and emendation of the description. Int $J$ Syst Bacteriol 46, 223-228.

Ivanova, E. P., Kiprianova, E. A., Mikhailov, V. V. \& 7 other authors (1998). Phenotypic diversity of Pseudoalteromonas citrea from different marine habitats and emendation of the description. Int $J$ Syst Bacteriol 48, 247-256.

Ivanova, E. P., Zhukova, N. V., Svetashev, V. I., Gorshkova, N. M., Kurilenko, V. V., Frolova, G. M. \& Mikhailov, V. V. (2000a). Evaluation of phospholipid and fatty acid compositions as chemotaxonomic markers of Alteromonas-like proteobacteria. Curr Microbiol 41, 341-345.

Ivanova, E. P., Chun, J., Romanenko, L. A., Matte, M. E., Mikhailov, V. V., Frolova, G. M., Huq, A. \& Colwell, R. R. (2000b). Reclassification of Alteromonas distincta Romanenko et al. 1995 as Pseudoalteromonas distincta comb. nov. Int J Syst Evol Microbiol 50, 141-144.

Ivanova, E. P., Sawabe, T., Lysenko, A. M., Gorshkova, N. M., Hayashi, K., Zhukova, N. V. I., Nicolau, D. V., Christen, R. \& Mikhailov, V. V. (2002). Pseudoalteromonas translucida sp. nov. and Pseudoalteromonas paragorgicola sp. nov., and emended description of the genus. Int J Syst Evol Microbiol 52, 1759-1766.

Ivanova, E. P., Bakunina, I. Y., Nedashkovskaya, O. I., Gorshkova, N. M., Alexeeva, Y. V., Zelepuga, E. A., Zvaygintseva, T. N., Nicolau, D. V. \& Mikhailov, D. V. (2003). Ecophysiological variabilities in ectohydrolytic enzyme activities of some Pseudoalteromonas species, P. citrea, P. issachenkonii, and P. nigrifaciens. Curr Microbiol 46, 6-10.

Ivanova, E. P., Gorshkova, N. M., Sawabe, T. \& 8 other authors (2004). Sulfitobacter delicatus sp. nov. and Sulfitobacter dubius sp. nov., respectively from a starfish (Stellaster equestris) and sea grass (Zostera marina). Int J Syst Evol Microbiol 54, 475-480.

Lucas-Elío, P., Solano, F. \& Sanchez-Amat, A. (2002). Regulation of polyphenol oxidase activities and melanin synthesis in Marinomonas mediterranea: identification of $p p o S$, a gene encoding a sensor histidine kinase. Microbiology 148, 2457-2466. 
Marmur, J. (1961). A procedure for the isolation of deoxyribonucleic acid from microorganisms. J Mol Biol 3, 208-218.

Marmur, J. \& Doty, P. (1962). Determination of the base composition of deoxyribonucleic acid from its thermal denaturation temperature. J Mol Biol 5, 109-118.

Perrière, G. \& Gouy, M. (1996). WWW-Query: an on-line retrieval system for biological sequence banks. Biochimie 78, 364-369.

Pomerantz, S. H. \& Murphy, V. V. (1974). Purification and properties of tyrosinases from Vibrio tyrosinaticus. Arch Biochem Biophys 160, 73-82.

Prokof'eva, N. G., Chaikina, E. L., Kicha, A. A. \& Ivanchina, N. V. (2003). Biological activities of steroid glycosides from starfish. Comp Biochem Physiol 134, 695-701.

Romanenko, L. A., Mikhailov, V. V., Lysenko, A. M. \& Stepanenko, V. I. (1995). A new species of melanin-producing bacteria of the genus Alteromonas. Microbiology (English translation of Mikrobiologiya) 64, 74-77.
Sasaki, T., Uchida, N. A., Uchida, H., Takasuka, N., Kamiya, H., Endo, Y., Tanaka, M., Hayashi, T. \& Shimizu, Y. (1985). Antitumor activity of aqueous extracts of marine animals. J Pharmacobiodyn $\mathbf{8}$, 969-974.

Sasser, M. (1997). MIDI: Technical note 102. Newark, DE: Microbial ID.

Smibert, R. M. \& Krieg, N. R. (1994). Phenotypic characterization. In Methods for General and Molecular Bacteriology, pp. 607-654. Edited by F. Gerhardt. Washington, DC: American Society for Microbiology.

Svetashev, V. I., Vysotskii, M. V., Ivanova, E. P. \& Mikhailov, V. V. (1995). Cellular fatty acid of Alteromonas species. Syst Appl Microbiol 18, 37-43.

Wayne, L. G., Brenner, D. J., Colwell, R. R. \& 9 other authors (1987). International Committee on Systematic Bacteriology. Report of the ad hoc committee on reconciliation of approaches to bacterial systematics. Int J Syst Bacteriol 37, 463-464. 